\title{
APLICAÇÃO DA METODOLOGIA MULTIDISCIPLINAR DE ESTUDO DAS GRANADAS MANTÉLICAS PARA AVALIAÇÃO DO POTENCIAL DIAMANTÍFERO DE KIMBERLITOS, EXEMPLO CLÁSSICO: PROVÍNCIA DE ARKHANGELSK, FEDERAÇÃO RUSSA
}

\author{
VIKTOR KONSTANTINOVICH GARANIN', WOLDEMAR IWANUCH ${ }^{2}$, GALINA PETROVNA KUDRIAVTSEVA ${ }^{\prime}$ \\ \& ELENA RUDOLFOVNA VASILEVA'
}

\begin{abstract}
RESUMO Este trabalho discorre sobre a aplicação da metodologia multidisciplinar de estudo das granadas de kimberlitos. Seu emprego no estudo dos três principais campos kimberlíticos da Província Diamantífera de Arkhangelsk, situada no nordeste da Plataforma Européia Oriental, permitiu identificar paragêneses minerais de rochas oriundas do manto e determinar granadas pertencentes a vários grupos químico-genéticos, incluindo os diamantíferos e altamente diamantíferos. As previsões de teores de diamantes nos vários pipes, efetuados com base no estudo das paragêneses das granadas e de suas frequêencias foram confirmadas ulteriormente por métodos diretos de avaliação.
\end{abstract}

Palavras-chave: metodologia multidisciplinar, granada, avaliação do potencial diamantífero, kimberlitos, Arkhangelsk, Federação Russa.

\begin{abstract}
APPLICATION OF THE MULTIDISCIPLINARY METHODOLOGY IN THE STUDY OF MANTELIC GARNETS FOR THE DIAMOND POTENTIAL EVALUATION IN KIMBERLITES, A CLASSICAL EXAMPLE: ARKHANGELSK DIAMOND PROVINCE, RUSSIAN

FEDERATION This paper aims to describe the application of a multidisciplinary methodology to study kimberlitic garnets. Its application, during the study of three main kimberlitic fields in the Arkhangelsk Diamondiferous Province situated in the northeast of the East European Platform, permitted to identify mineral paragenesis from mantle rocks, and to find garnets pertaining to several chemical-genetic groups, including those which are diamondiferous and highly diamondiferous. Diamond grade previsions made for several pipes, on the basis of the garnet paragenesis and its frequency study, were further confirmed by direct methods of evaluation.
\end{abstract}

Keywords: multidisciplinary methodology, garnet, diamond potential evaluation, kimberlites, Arkhangelsk, Russian Federation

INTRODUÇÃO Um dos maiores feitos dos geólogos prospectores russos no final da década de 1970 e início dos anos 1980 foi a descoberta e a definição da Província Diamantífera de Arkhangelsk, nordeste da Plataforma Européia Oriental, norte da parte européia da Federação Russa (Fig.1). Durante os trabalhos de prospecção e pesquisa foram identificados e estudados cerca de 100 pipes constituídos por vários tipos de kimberlitos, melilititos e basaltos, compreendendo 10 campos de rochas magmáticas, dos quais, três (Zolotitskoc, Verkhotinskoe e Kepinskoe) são diamantíferos. A localização

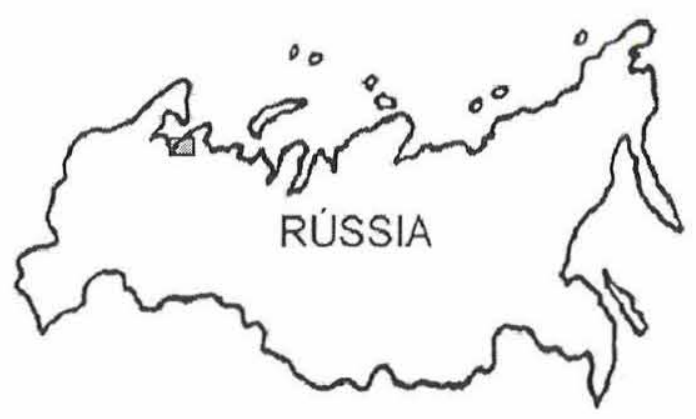

Figura 1- Localização da Província Diamantífera de Arkhangelsk em termos do território da Federação Russa. de oito dos dez dos campos magmáticos dessa Província pode ser vista na figura 2 .

Ao final dos 1980, os 6 corpos diamantíferos do Campo Kimberlítico de Zolotitskoe, situado na porção central da Província, foram agrupados no que se chama hoje de Jazida Diamantífera de M. V. Lomonossov, avaliada em US\$14 bilhões (Bogatikov et al.1999). Em 1996, no Campo Kimberlítico de Verkhotinskoe foi descoberto o pipe diamantífero V. Grib, avaliado em US\$ 4 bilhões (Bogatikov et al.1999). A descoberta desse corpo ampliou consideravelmente as perspectivas de novos achados de pipes diamantíferos tanto na província considerada, pelo fato de normalmente ocorrerem em clusters, como em toda a porção européia da Rússia, por existirem outras áreas com rochas magmáticas geoquimicamente semelhantes, como na região de Timan, situada à nordeste de Arkhangelsk. Atualmente, o conjunto das jazidas da região de Arkhangelsk constitui uma das grandes províncias diamantíferas do mundo. A descrição da geologia regional e local, bem como dos corpos kimberlíticos e de suas características petrográficas, geoquímicas e mineralógicas encontra-se em Bogatikov et al. (1999).

O Método Multidisciplinar de estudo dos minerais satélites do diamante (MSD) e dos kimberlitos e/ou lamproitos como um todo, além de ter contribuído significativamente na descoberta de novas jazidas nessa região da Federação Russa, é ferramenta ideal para os novos paradigmas da mineração, visto que permite reduzir impactos ambientais e efetuar, a custos sensivelmente menores, trabalhos de prospecção, pesquisa e avaliações do potencial diamantífero de kimberlitos ou lamproitos. No caso da Federação Russa, onde os ambientes geológicos são tão diversificados quanto as paisagens naturais,

I Laboratório de Diamantes, Faculdade de Geologia, Universidade Estatal de Moscou, 119899 Moscou, Vorobevy Gory, Rússia

2 Laboratório dos Elementos do Bloco-f, Departamento de Química Fundamental, Instituto de Química, Universidade de São Paulo, Av. Prof.Lineu Prestes,748, Bloco-8T. CEP: 05508-900 São Paulo-SP wold@uol.com.br 


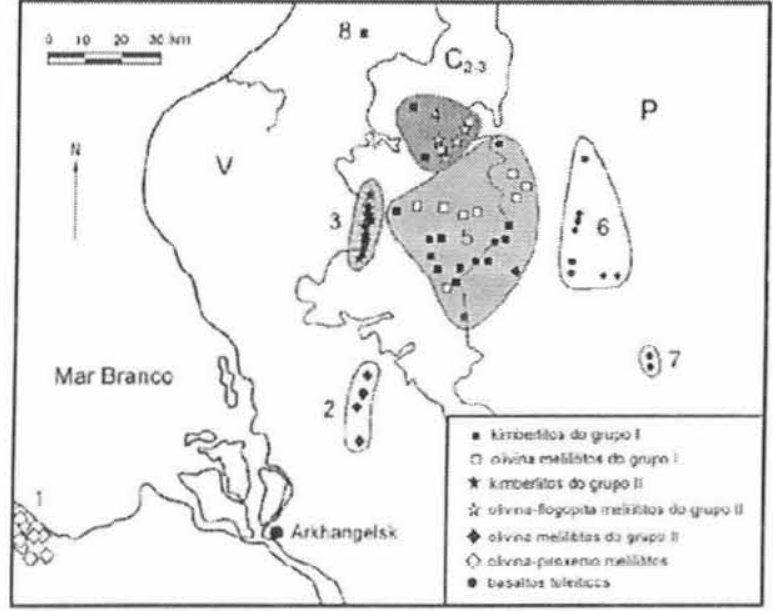

Figura 2 - Localização dos focos de magmatismo na Província Diamantífera de Arkhangelsk. Campos de magmatismo: 1Nenoksa (Península de Onezh); 2- Izhmozerskoe; 3Zolotitskoe; 4-Verkhotinskoe; 5- Kepinskoe; 6-Turinskoe; 7 Poltinskoe; 8- Melskoe. Rochas do: V-Vendiano; CCarbonífero; P-Permiano. (Segundo Bogatikov et al.1999).

o uso desta metodologia é de fundamental importância para realizar os trabalhos de prospecção e pesquisa por parte dos serviços geológicos regionais e companhias de exploração de jazidas de diamantes do país, particularmente a ALROSA Company Ltd., empresa paraestatal responsável pela pesquisa do diamante na Província Diamantífera da Yakutia, nos Urais e no sul da região de Krasnoyarsk, Sibéria Central, em vista das novas e rigorosas leis de proteção ambiental do país.

O Método Multidisciplinar envolve a caracterização qualitativa e quantitativa de amostras estatisticamente representativas de MSD de origem mantélica, como granada, clinopiroxênio (eclogítico e ultrabásico), olivina, ilmenita, e cromoespinélio, amostrados em coletores sedimentares, mantos de intemperismo ou em kimberlitos e/ou lamproitos inalterados. O método envolve também o estudo de minerais da matriz de kimberlitos (e/ou lamproitos) de testemunhos de sondagem ou amostras de mão. Em linhas gerais, o método abrange estudos ópticos, microscopia eletrônica de varredura, espectroscopia no infravermelho, espectroscopia óptica de absorção, análise química instrumental em microssonda eletrônica, determinação dos parâmetros magnéticos (suscetibilidade magnética, magnetizações $\mathrm{S}_{\mathrm{v} 0}, \mathrm{I}_{S}, \mathrm{I}_{\mathrm{rS}}$, temperatura Curie, $\mathrm{I}_{\mathrm{rS}} / \mathrm{I}_{\mathrm{S}}, \mathrm{H}_{0.9}$ ' $\mathrm{H}_{0.1}$,etc), diversos cálculos matemático-estatísticos, discriminação dos MSD segundo classificações químico-genéticas especificas, estimativa da profundidade de geração, da velocidade relativa de esfriamento e das condições de PT do magma kimberlítico (e/ou lamproítco), cálculos termodinâmicos, etc. Como um todo, objetiva determinar a presença de paragêneses diamantíferas e, a partir destas, o potencial primário diamantífero de um determinado pipe e, pelo estudo dos microcristais de minerais óxidos, o grau de preservação do diamante. Enfatiza-se que foram elaboradas classificações químico-genéticas para todos os MSD. O método foi desenvolvido no Laboratório dos Diamantes da Faculdade de Geologia da Universidade Estatal de Moscou, Federação Russa, para avaliar o potencial diamantífero de kimberlitos e/ou lamproitos por métodos indiretos. Uma descrição mais alongada, ainda que como
Extended Abstracts em língua inglesa de parte do mesmo foi apresentada por Garanin \& Kudryavtseva (1991), Garanin et al. (1991a), Garanin et al.(1998), e dos minerais óxidos da matriz do kimberlito em Garanin et al. (1991b).

As técnicas de amostragem de MSD, tanto nas várias fases de prospecção (para se chegar ao kimberlito), quanto na pesquisa (do kimberlito) não são enfocadas neste trabalho, podendo ser procuradas em trabalhos específicos como os de Kharkiv (1978), Zubarev (1984), Zakharova (1989), Afanasiev (1991), Kharkiv et al.(1995) e outros. A sugestão é extensiva para as técnicas de tratamento de amostras para obter concentrados monominerálicos, como descritos em detalhe por Berlinskiy (1988, 1991).

Neste trabalho descreveremos de modo mais amplo apenas o emprego da granada para os fins de prospecção e avaliação do potencial diamantífero de kimberlitos, considerando na análise apenas a região de Arkhangelsk, a qual pode ser considerada como modelo de diversidade de problemas e dificuldades na condução dos trabalhos de prospecção e pesquisa do diamante, tais como a difícil reposição da flora original e sistemas ecológicos muito frágeis, dentre outros.

Na Província Diamantífera de Arkhangelsk, dentre os MSD, a granada e o cromoespinélio ocorrem juntos e com maior freqüência que os demais minerais do grupo nos concentrados da fração pesada. Como as auréolas de dispersão de minerais pesados apresentam teores muito pequenos de MSD, o uso de técnicas tradicionais, que discriminam apenas alguns dos MSD, implicaria na remoção de grande volume de material para a obtenção de amostras representativas de grãos de MSD. Para evitar este transtorno (econômico, ambiental e logístico), o Método Multidisciplinar de estudo dos MSD quando aplicado às várias fases de prospecção, pesquisa e avaliação do potencial diamantífero de kimberlitos permite que se trabathe com amostras relativamente pequenas (por exemplo: com concentrados da fração pesada de minerais obtidos de coletores sedimentares, testemunhos de sondagem, etc.) de modo a se dispensar extensos trabalhos mineiros e agressões ao meio ambiente. O Método permite ampliar significativamente o volume de informações que se obtém de um determinado alvo de pesquisa pelo uso de técnicas de análise e interpretação mais refinadas.

No caso específico da granada, esses dados são obtidos pelo estudo do tipomorfismo, da composição química, das características espectroscópicas, das feições superficiais dos MSD e da sua pertinência paragenética. Cabe lembrar que a granada é um dos minerais mais importantes na determinação indireta da presença ou não do diamante no kimberlito.

Este trabalho enfoca especificamente o estudo das granadas.

Como mencionado, a Metodologia Multidisciplinar de estudos dos MSD possibilita conduzir de nova maneira os trabalhos de prospecção e pesquisa do diamante, resolver, aliás, inúmeros problemas relacionados a prognose e à pesquisa: regionalização mineralógica de territórios ou áreas, identificação e tipificação de auréolas de dispersão dos MSD, caracterização mineralógica de corpos, identificação dos corpos diamantíferos, estudo dos zoneamentos vertical e horizontal, etc.

É importante salientar que no estudo dos MSD pelo Método Multidisciplinar, existe um único processo tecnológico e que suas etapas se sucedem ininterruptamente na medida em que cada fase de estudos possui uma importância e especificidade intrínseca.

A descrição individualizada e detalhada de cada um dos 
grãos de MSD, sobretudo das granadas, é fundamental, pois permite conhecer ainda na fase inicial da prospecção, a evolução dos MSD nas auréolas de dispersão durante o transporte e alteração supergênica em coletores sedimentares. A determinação de todas as paragêneses minerais com base nas classificações químico-genéticas elaboradas, permite identificar as associações e conhecer o comportamento dos minerais de fontes primárias ou secundárias diferentes durante a sua caracterização. Essa é uma etapa muito importante do trabalho de prospeç̧ão, já que é possível ligar as auréolas de dispersão de minerais pesados com os corpos kimberlíticos a partir dos quais se originaram (área fonte) e, individualizar as áreas com prováveis novos corpos kimberlíticos diamantíferos ou não.

\section{METODOLOGIA MULTIDISCIPLINAR EMPREGADA} AO ESTUDO DA GRANADA O estudo da granada por meio da metodologia multidisciplinar é efetuado em várias etapas sucessivas, a seguir descritas.

\begin{abstract}
Primeira etapa Estudo morfológico das amostras sob lupa binocular com posterior definição de suas particularidades micromorfológicas em microscópio eletrônico de varredura (em parte das amostras). Durante esse estudo, a descrição das amostras se faz com base em quatro características, que determinam o aspecto externo do mineral, istso é, cor (rosa, laranja, comuns para granadas de paragênese eclogítica e vermelha e lilás, indício de granada de paragênese ultrabásica); grau de preservação (indivíduos inteiros, fraturados, fragmentos e lascas); forma dos grãos (facetados, ovalado-arredondados, irregulares); aspecto da superfície (lisa, em telhado de ardósia, levemente foscada ou deslustrada, altos-baixos). Cada uma dessas características tem sua própria importância genética. Os histogramas elaborados com as amostras estatisticamente significativas com indicação de todas características indicadas permitem determinar preliminarmente se existe ou não associação diamantífera, e obter informações iniciais quanto ao grau de preservação dos minerais satélites e dos cristais de diamante. Os detalhes dos procedimentos para descrição visual dos grãos de MSD e da sua importância, podem ser encontrados em Afanasev et al. (1986).
\end{abstract}

Segunda etapa Estudo óptico-colorimétrico da granada já separada conforme os quatro grupos de cor. O espectro de cada tipo de granada segundo a cor, caracteriza-se por um conjunto de bandas de absorção devidas a uma determinada combinação de centos cromóforos, a sua posição no espectro, a variação da concentração dos centros cromóforos opticamente ativos e do teor de cálcio e magnésio no mineral. Para efetuar a classificação paragenética preliminar das granadas, utilizou-se o "Diagrama de Coloração Modificado" elaborado por Matsyuk et al. (1985), no qual aparecem vários campos indicando as diversas associaçōes paragenéticas de granadas mantélicas. Nessa fase, o material estudado e estatisticamente representativo, adquire significado qualitativo e quantitativo, uma vez que está funcionalmente relacionado com as características estruturais e com a composição química da granada. Os resultados obtidos permitem avaliar qual porção das granadas é de paragênese ultrabásica e eclogítica, e dentre elas reconhecer quais são de paragênese diamantífera. Os detalhes da metodologia de obtenção, processamento e interpretação de dados espectroscópicos de absorção, não serão aqui apresentados, podendo ser encontrados em Matsyuk et al. (1985) e Matsyuk (1992). Exemplo de aplicação dessa metodologia de estudo de granadas de kimberlitos brasileiros pode ser visto em Iwanuch et al. (1999).

Terceira etapa A análise em microssonda eletrônica de cada um dos grupos de granada identificados tem por objetivos: a definição mais acurada das suas paragêneses; a subdivisão das de paragênese diamantífera, através do estudo da composição química, do zoneamento, da composição normativa, e das inclusões minerais na granada; a identificação das heterogeneidades minerais e cálculo das condições termodinâmicas de cristalização da granada das várias paragêneses identificadas. O tratamento matemático dos dados nessa etapa dos estudos, permite identificar e separar em diversos grupos a população de granada da amostra estudada, com base na similitude da sua composição química, os grupos identificados, por seu turno, vão se enquadrar nos diversos grupos químico-genéticos de granada encontrados em kimberlitos e anteriormente definidos por Garanin et al. (1991). Um bosquejo da classificação químico-genética da granada é apresentado no item subseqüente desse artigo.

\section{CLASSIFICAÇ̃̃O QUÍMICO-GENÉTICA DA GRANA-}

DA MANTÉLICA A chave do método consiste em tipificar as granadas estudadas por meio do uso da classificação químico-genética elaborada a partir dos dados químicos da granada de xenólitos de rochas mantélicas ultrabásicas e básicas diamantíferas ou não.

Essa classificação (Garanin et al. 1991) foi desenvolvida a partir de um banco de dados formado por centenas de análises químicas do mineral compiladas da literatura mundial e de dados obtidos pelos próprios autores. O banco de dados baseiase em 375 análises químicas de granadas de paragênese eclogítica, abarcando todos os tipos de eclogitos de origem mantélica, diamantíferos ou não, bem como análises de granadas dessa paragênese inclusas em diamantes ou intercrescidas com eles e 460 análises de granadas de paragênese ultrabásica, encontradas em xenólitos de rochas, ou associadas a diamantes ou inclusas neles.

No desenvolvimento e na elaboração da classificação químico-genética, utilizou-se o cluster analysis (análise por agrupamento). As características gerais do método e do algoritmo utilizado podem ser encontradas em Garanin et al. (1990). Outrossim, cabe lembrar que ele difere substancialmente em muitos aspectos do empregado pelos precursores da utilização do método Dawson \& Stephens (1975) e de outros que se serviram do mesmo método para elaborar suas classificações, como Danchin \& Wyatt (1979), Zolnikov et al. (1981), Safronov \& Nikolaev (1985) e Jago \& Mitchell (1986), e marcadamente quanto ao estabelecimento do número de paragêneses de rochas mantélicas diamantíferas com granada associada. A análise de cada uma das classificações citadas por fugir do escopo deste trabalho não será aqui realizada, podendo ser encontrada em Garanin et al. (1990).

A Tabela 1 apresenta a classificação químico-genética das granadas e a Tabela 2 a variação da composição química das granadas associadas a diversos tipos de rochas (xenólitos) ultrabásicas e básicas de origem mantélica. Grupos altamente diamantíferos compreenderam granadas com $90 \%$ de associação com diamante, nos grupos diamantíferos a associação situou-se entre $50 \%$ e $90 \%$, os fracamente diamantíferos a menos de $50 \%$, e paragêneses não diamantíferas as isentas de diamante associado ao grupo. 
Tabela I - Classificação químico-genética da granada mantélica de paragênese ultrabásica e eclogítica.

\begin{tabular}{|c|c|c|c|c|c|c|c|}
\hline \multirow{2}{*}{$\begin{array}{l}\text { Número do } \\
\text { grupo } \\
\text { Químico- } \\
\text { genético }\end{array}$} & \multirow[b]{2}{*}{ Associação genética da granada } & \multicolumn{5}{|c|}{ Número de análises de granadas } & \multirow[b]{2}{*}{ Composiçãonormativa } \\
\hline & & Total & \begin{tabular}{|c|} 
De inclusōes \\
no diamante
\end{tabular} & \begin{tabular}{|c|}
$\begin{array}{c}\text { De intecrescimentos } \\
\text { com o diamante }\end{array}$ \\
\end{tabular} & \begin{tabular}{|c|} 
De xenólitos \\
diamantíferos
\end{tabular} & \begin{tabular}{|c|} 
De xenólitos \\
não \\
diamantíferos \\
\end{tabular} & \\
\hline 1 & Dunitos e harzburgitos altamente diamantíferos & 158 & 128 & 5 & 18 & 7 & Almnandina-knorringita-piropo \\
\hline 2 & $\begin{array}{l}\text { Peridotitos diamantíferos com granada mediana a altamente cromífera; intercrescimentos } \\
\text { de granada-clinopiroxênio-espinélio }\end{array}$ & 14 & 6 & 1 & 0 & 7 & Uvarovita-almandina-knorringita-piropo \\
\hline 3 & Lherzolitos eqüigranulares diamantíferos com granada altamente cromífera & 24 & 12 & 1 & 1 & 10 & Kmoringita-uvarovita-almandina-piropo \\
\hline 4 & Lherzolitos equigranulares diamantíferos com granada medianamente cromífera & 54 & 13 & 7 & 2 & 32 & Uvarovita-almandina-piropo (+knorringita) \\
\hline 5 & Lherzolitos eqüigranulares diamantíferos com granada de baixo a médio teor de $\mathrm{Cr}$ & 29 & 11 & 10 & 0 & 8 & Uvarovita-almandina-piropo (+knorringita) \\
\hline 6 & Wehrlitos diamantíferos & 7 & 4 & 0 & 0 & 3 & $\begin{array}{l}\text { Grossularia-almandina-uvarovita-piropo } \\
\text { (Ti-andradita) }\end{array}$ \\
\hline 7 & $\begin{array}{l}\text { Lherzolitos eqüigranulares (as vezes cisalhados) pouco diamantíferos com granada de alto } \\
\text { teor em } \mathrm{Cr} \text {. Ti e Ca. }\end{array}$ & 13 & 1 & 0 & 0 & 12 & $\begin{array}{l}\text { Uvarovita-almandina-knorringita-piropo } \\
\text { (Ti-andradita, andradita) }\end{array}$ \\
\hline 8 & $\begin{array}{l}\text { Ilmenita Iherzolitos equigranulares (freqüentemente cisalhados) pouco diamantíferos com } \\
\text { granadas titaníferas de baixo cromo }\end{array}$ & 41 & 4 & 0 & 3 & 34 & $\begin{array}{l}\text { Almandina-piropo } \\
\text { (grossuläria) }\end{array}$ \\
\hline 9 & Lherzolitos e websteritos com granada de baixo cromo & 20 & 0 & 0 & 0 & 20 & Grossulária-uvarovita-almandina-piropo \\
\hline 10 & Illmenita wehrlitos e nódulos monominerálicos de granada & 16 & 0 & 0 & 0 & 16 & Andradita-almandina-piropo \\
\hline 11 & Piroxenitos ferromagnesianos \pm ilmeníticos & 5 & 0 & 0 & 0 & 5 & Grossulária-almandina-piropo \\
\hline 12 & Alcremitos magnesianos & 6 & 0 & 0 & 0 & 6 & Almandina-piropo \\
\hline 13 & Alcremitos cálciomagnesianos & 18 & 0 & 0 & 0 & 18 & Almandina-grossulária-piropo \\
\hline 14 & Granadas zonadas com inclusōes de cromoespinélios & 19 & 0 & 0 & 0 & 19 & Almnandina-uvarovita-piropo (+knorringita) \\
\hline 15 & Granadas zonadas com inclusōes de ilmenita & 12 & 0 & 0 & 0 & 12 & Grossulária-uvarovita-almandina-piropo \\
\hline 16 & Intercrescimentos de granada-ilmenita ( \pm clinopirôxenio) & 25 & 0 & 0 & 0 & 25 & Uvarovita-grossulária-almandina-piropo \\
\hline 17 & Inclusões no diamante & 4 & 4 & 0 & 0 & 0 & $\begin{array}{l}\text {-Majorita"** (solução sólida granadar } \\
\text { puiroxênio) }\end{array}$ \\
\hline 18 & Eclogitos ferromagnesianos altamente titaníferos altamente diamantifferos & 12 & 11 & 1 & 0 & 0 & $\begin{array}{l}\text { Andradita - Ti-andradita-grossulária- } \\
\text { almandina-piropo }\end{array}$ \\
\hline 19 & Ilmenita-rutilo eclogitos ferromagnesianos diamantíferos & 129 & 29 & 23 & 11 & 59 & $\begin{array}{l}\text { Ti-andradita-andradita-grossulária- } \\
\text { almandina-piropo }\end{array}$ \\
\hline 20 & Eclogitos ferromagnesianos diamantíferos & 101 & 16 & 6 & 23 & 56 & Grossulária-almandina-piropo \\
\hline 21 & Eclogitos aluminosos diamantíferos & 88 & 1 & 3 & 56 & 28 & $\begin{array}{l}\text { Grossulária-almandina-piropo; } \\
\text { Grossulária-piropo-almandina }\end{array}$ \\
\hline 22 & Grospiditos altamente cálcicos & 4 & 0 & 0 & 0 & 4 & $\begin{array}{l}\text { Ti-andradita-andradita-almandina-piropo- } \\
\text { grossulária }\end{array}$ \\
\hline 23 & Grospiditos diamantíferos & 2 & 2 & 0 & 0 & & \\
\hline 24 & Ilmenita-rutilo eclogitos magnesianos diamantíferos & 5 & 1 & 1 & 1 & 2 & $\begin{array}{l}\text { Ti-andradita-andradita-grossulária- } \\
\text { uvarovita-almandina-piropo }\end{array}$ \\
\hline 25 & Eclogitos magnesianos altamente cromíferos pouco diamantíferos & 6 & 0 & 0 & 2 & 4 & $\begin{array}{l}\text { Ti-andradita-andradita-grossulária- } \\
\text { uvarovita-almandina-piropo }\end{array}$ \\
\hline 26 & Eclogitos ferromagnesianos altamente silicosos & 5 & 0 & 0 & 0 & 5 & Ti-andradita-grossulária-almandina-piropo \\
\hline 27 & Eclogitos ferromagnesianos manganíferos & 9 & 0 & 0 & 1 & 8 & $\begin{array}{l}\text { Espessartita-Ti-andradita-andradita- } \\
\text { grossulária-almandina-piropo }\end{array}$ \\
\hline 28 & Distênio eclogitos e grospiditos altamente cromíferos & 7 & 0 & 0 & 0 & 7 & $\begin{array}{l}\text { Andradita-uvarovita-almandina-piropo- } \\
\text { grossulária }\end{array}$ \\
\hline 29 & Rutilo eclogittos altamente ferriferos & 14 & 0 & 0 & 0 & 14 & $\begin{array}{l}\text { Ti-andradita-andradita-piropo-grossuläria- } \\
\text { almandina }\end{array}$ \\
\hline 30 & Rochas eclogitóides & 23 & 0 & 0 & 0 & 23 & Grossulária-almandina-piropo \\
\hline
\end{tabular}

Nota": para a granada dessa composição não se aconselha o emprego do cálculo normativo de Sobolev (1974), pois apresenta solução sólida com clinopiroxênio. 
Tabela 2 - Parâmetros da composição química da granada dos diversos tipos químico-genéticos.

\begin{tabular}{|c|c|c|c|c|c|c|c|c|c|c|}
\hline & $\mathrm{SiO}_{2}$ & $\mathrm{TiO}_{2}$ & $\mathrm{Al}_{2} \mathrm{O}_{3}$ & $\mathrm{Cr}_{2} \mathrm{O}_{3}$ & $\mathrm{Fe}_{2} \mathrm{O}_{3}$ & $\mathrm{FeO}$ & $\mathrm{MnO}$ & $\mathrm{MgO}$ & $\mathrm{CaO}$ & $\mathrm{Na}_{2} \mathrm{O}$ \\
\hline \multirow[t]{2}{*}{1} & 40.10 .44 .00 & $0.00-0.40$ & $10.65-20.95$ & $2.75-15.94$ & $0.00 \cdot 2.80$ & $3.00-7.63$ & $0.17-0.50$ & $18.78-25.54$ & $0.52-7.52$ & $0.00-0.10$ \\
\hline & 41.42 & 0.11 & 15.06 & 11.19 & 1.02 & 5.39 & 0.29 & 22.69 & 2.77 & 0.02 \\
\hline \multirow[t]{2}{*}{2} & $40.00-42.66$ & $0.00 \cdot 0.82$ & $14.42-19.90$ & $4.97-10.56$ & $0.00-2.42$ & $4.27 \cdot 7.19$ & $0.00 \cdot 0.77$ & $18.00-23.70$ & $1.80-7.06$ & $0.00 \cdot 0.10$ \\
\hline & 41.56 & 0.24 & 17.18 & 8.47 & 1.00 & 5.97 & 0.08 & 22.19 & 3.44 & 0.02 \\
\hline \multirow[t]{2}{*}{3} & $39.96-42.20$ & $0.00 \cdot 0.35$ & $15.91-19.81$ & $6.00-10.72$ & $0.00-2.20$ & $4.50-9.60$ & $0.23 \cdot 0.54$ & 18.24 .21 .10 & $2.25 \cdot 7.06$ & $0.00 \cdot 0.09$ \\
\hline & 41.19 & 0.13 & 17.44 & 8.12 & 0.63 & 6.63 & 0.36 & 19.94 & 5.45 & 0.02 \\
\hline \multirow[t]{2}{*}{4} & $40.90-42.88$ & $0.00-0.21$ & $17.61-22.30$ & $3.60 \cdot 7.14$ & $0.00-2.54$ & $4.64-7.95$ & $0.13-0.45$ & $18.52-23.71$ & $2.33 \cdot 6.68$ & $0.00-0.07$ \\
\hline & 41.86 & 0.08 & 19.79 & 5.21 & 0.64 & 6.31 & 0.31 & 20.93 & 5.05 & 0.02 \\
\hline \multirow[t]{2}{*}{5} & $40.80-44.80$ & $0.12 \cdot 0.68$ & $16.09-23.20$ & $1.15-7.31$ & $0.00-1.90$ & $4.45-8.72$ & $0.21-0.41$ & $\underline{18.68-23.60}$ & $1.53-6.30$ & $0.00-0.10$ \\
\hline & 42.42 & 0.32 & 20.15 & 4.15 & 0.64 & 6.42 & 0.30 & 21.36 & 4.42 & 0.02 \\
\hline \multirow[t]{2}{*}{6} & $40.30-41.00$ & $0.12-0.50$ & $14.70-17.17$ & $7.15-9.61$ & $0.00 \cdot 1.60$ & $3.55-8.32$ & $0.24 \cdot 0.39$ & $14.10-17.66$ & $9.69-13.50$ & $0.00 \cdot 0.13$ \\
\hline & 40.81 & $0.4 ?$ & 16.24 & 8.10 & 0.94 & 4.89 & 0.30 & 15.39 & 12.24 & 0.05 \\
\hline \multirow[t]{2}{*}{7} & $40.70-41.60$ & $0.75-1.91$ & $11.60-16.90$ & $5.99-12.60$ & $0.00 \cdot 2.94$ & $4.34-7.10$ & $0.18-0.37$ & $18.00-20.50$ & $5.41-7.62$ & $0.00-0.19$ \\
\hline & 40.89 & 1.13 & 14.71 & 9.34 & 1.80 & 5.79 & 0.30 & 19.19 & 6.62 & 0.03 \\
\hline \multirow[t]{2}{*}{8} & 40.75 .43 .80 & $0.00 \cdot 1.28$ & $19.05-24.80$ & $0.00-6.59$ & $0.00 \cdot 3.04$ & $5.96-12.64$ & $0.00 \cdot 0.41$ & 17.22 .21 .99 & 2.93 .7 .57 & $0.00-0.18$ \\
\hline & 41.18 & 0.72 & 21.46 & 1.52 & 1.31 & 8.46 & 0.21 & 20.31 & 4.33 & 0.05 \\
\hline \multirow[t]{2}{*}{9} & $40.91-42.73$ & $\underline{0.00-0.30}$ & $18.28-24.20$ & $\underline{0.12-5.89}$ & $0.00-2.14$ & $6.46-11.25$ & $0.28-0.61$ & $16.32-21.78$ & $3.84-7.29$ & $0.00-0.09$ \\
\hline & 42.06 & 0.11 & 21.97 & 2.19 & 0.61 & 8.74 & 0.45 & 19.50 & 5.16 & 0.03 \\
\hline \multirow[t]{2}{*}{10} & $39.00 \cdot 41.40$ & $\underline{0.42-1.11}$ & $19.80-23.04$ & $0.12-1.65$ & 1.43 .3 .00 & $5.36-10.92$ & $\underline{0.11-0.79}$ & $14.10-21.98$ & $\underline{4.66-11.00}$ & $0.00-0.18$ \\
\hline & 40.28 & 0.82 & 21.58 & 0.85 & 2.47 & 8.54 & 0.38 & 18.10 & 7.24 & 0.06 \\
\hline \multirow[t]{2}{*}{11} & $39.60-41.28$ & $0.00-0.14$ & $20.30-24.14$ & $0.00 \cdot 1.93$ & $0.00-3.20$ & $12.48-20.50$ & $0.42-0.76$ & $12.00-16.44$ & $4.55-5.88$ & $0.00-0.03$ \\
\hline & 40.20 & 0.08 & 21.94 & 0.67 & 1.29 & 16.90 & 0.51 & 13.55 & 5.25 & 0.01 \\
\hline \multirow[t]{2}{*}{12} & $4.19-43.90$ & $\underline{0.01 \cdot 0.03}$ & $23.25-24.30$ & $0.10-0.72$ & $0.00-0.35$ & $4.86-7.32$ & $0.21 \cdot 0.34$ & $22.81-26.00$ & $0.64-2.44$ & - \\
\hline & 43.60 & 0.02 & 24.02 & 0.33 & 0.16 & 6.01 & 0.26 & 24.51 & 1.47 & \\
\hline \multirow[t]{2}{*}{13} & 40.40 .42 .92 & $0.01-0.27$ & $21.18-24.60$ & $0.00-2.67$ & $0.00 \cdot 0.80$ & $5.28-10.60$ & $\underline{0.05-0.33}$ & $13.00-17.38$ & $7.90 \cdot 14.12$ & . \\
\hline & 41.70 & 0.14 & 23.32 & 0.30 & 0.26 & 8.14 & 0.23 & 15.39 & 11.14 & \\
\hline 14 & 39.80 .40 .40 & $\underline{0.24-0.76}$ & $13.10-17.55$ & $6.31-10.75$ & $0.00-2.55$ & $5.93 \cdot 10.60$ & $0.41-0.93$ & $10.28-16.60$ & $6.73 \cdot 15.40$ & $0.00-0.29$ \\
\hline & 39.56 & 0.52 & 15.31 & 8.74 & 1.09 & 9.29 & 0.62 & 13.35 & 10.32 & 0.06 \\
\hline 15 & $39.82-41.67$ & $\underline{0.46-0.70}$ & $\underline{16.70 \cdot 22.15}$ & $1.61-6.58$ & $\underline{0.00 \cdot 2.06}$ & $9.38 \cdot 12.14$ & $\underline{0.46-0.65}$ & $12.25 \cdot 16.30$ & $5.82-10.45$ & $0.00-0.27$ \\
\hline & 40.63 & 0.58 & 19.48 & 4.07 & 0.70 & 10.76 & 0.54 & 13.96 & 8.68 & 0.09 \\
\hline 16 & $40.70-42.02$ & $0.05-0.61$ & $17.68-21.82$ & $0.84 \cdot 4.89$ & $0.00-2.62$ & $8.55-12.63$ & $0.10-0.34$ & $13.62-12.30$ & $5.11-9.69$ & - \\
\hline & 41.41 & 0.41 & 20.07 & 2.52 & 1.35 & 10.73 & 0.28 & 15.56 & 8.13 & \\
\hline 17 & $42.08-47.73$ & $\underline{0.78 \cdot 1.21}$ & $11.29-18.31$ & $\underline{0.01 \cdot 0.20}$ & & $9.77 \cdot 14.74$ & $\underline{0.19 \cdot 0.29}$ & $10.31-22.05$ & $\underline{7.11-11.93}$ & $0.33-1.08$ \\
\hline & 44.60 & 0.99 & 15.18 & 0.08 & & 12.00 & 0.26 & 16.01 & 10.05 & 0.66 \\
\hline 18 & $39.50-40.51$ & $0.83 \cdot 1.25$ & $20.20-22.60$ & $0.00-0.11$ & & $15.66-20.10$ & $0.26-0.39$ & $7.44-11.90$ & $7.45-18.40$ & $0.26-0.35$ \\
\hline & 40.08 & 1.00 & 21.20 & 0.02 & & 17.91 & 0.32 & 9.69 & 9.96 & 0.22 \\
\hline 19 & 38.30 .42 .93 & $\underline{0.00-0.71}$ & $\underline{19.52-23.60}$ & $0.00 \cdot 0.27$ & & $\underline{11.59 \cdot 28.70}$ & $\underline{0.17-0.84}$ & $\underline{7.50-17.30}$ & $\underline{2.50-14.28}$ & $0.00 \cdot 0.28$ \\
\hline & 40.13 & 0.27 & 22.05 & 0.05 & & 18.79 & 0.53 & 11.22 & 7.19 & 0.09 \\
\hline 20 & $40.16-43.48$ & $0.00-1.02$ & $20.80-24.10$ & $0.00-0.68$ & & $7.40 \cdot 18.52$ & $0.00-0.61$ & $13.06-21.69$ & $3.12-9.40$ & $0.00 \cdot 0.35$ \\
\hline & 41.66 & 0.30 & 22.67 & 0.10 & & 13.55 & 0.33 & 16.25 & 5.38 & 0.10 \\
\hline 21 & $38.32-41.78$ & $0.01 \cdot 0.79$ & $21.03-23.80$ & $0.00-18.10$ & & $5.34-18.10$ & $\underline{0.00 \cdot 0.75}$ & $3.70-15.60$ & $2.55 \cdot 20.30$ & 0.000 .35 \\
\hline & 40.58 & 0.27 & 22.69 & 0.09 & & 10.84 & 0.20 & 11.53 & 13.59 & 0.09 \\
\hline 22 & $35.59 \cdot 39.90$ & $\underline{0.06 \cdot 0.48}$ & $\underline{21.00 \cdot 21.50}$ & $\underline{0 \wedge 00.0 .04}$ & & $2.42-10.29$ & $\underline{0.00 \cdot 0.14}$ & $\underline{0.81-5.36}$ & $26.63-34.20$ & $0.00-0.14$ \\
\hline & 38.77 & 0.21 & 21.22 & 0.02 & & 4.92 & 0.06 & 2.45 & 31.13 & 0.04 \\
\hline 23 & $39.00-39.30$ & 1.44 .1 .79 & $20.00-21.00$ & $0.09-0.19$ & & $2.92-6.22$ & $\underline{0.00-0.15}$ & $\underline{1.91-2.38}$ & $\underline{28.70-32.40}$ & $0.22-0.30$ \\
\hline & 39.15 & 1.62 & 20.50 & 0.14 & & 4.57 & 0.08 & 2.37 & 30.55 & 0.26 \\
\hline 24 & $40.01-43.40$ & $0.31-0.72$ & $21.24-24.59$ & $\underline{0.00-1.96}$ & & $\underline{6.55 \cdot 12.14}$ & $\underline{0.14-0.44}$ & $17.61-23.85$ & $2.73 \cdot 6.22$ & $0.04-0.12$ \\
\hline & 41.24 & 0.49 & 22.60 & 0.50 & & 9.31 & 0.27 & 21.45 & 3.81 & 0.09 \\
\hline 25 & 41.21 .44 .63 & $\underline{0.00-0.39}$ & $19.20-21.60$ & 2.13 .5 .50 & & $5.87-7.56$ & $\underline{0.25-0.59}$ & $18.70-21.20$ & $3.97-8.51$ & $0.00-0.13$ \\
\hline & 42.10 & 0.14 & 20.11 & 4.41 & & 7.02 & 0.38 & 20.25 & 5.44 & 0.04 \\
\hline 26 & $42.77 .45 .3 \mathrm{~s}$ & $\underline{0.16 \cdot 0.34}$ & $20.25-22^{\wedge} 33$ & $0.03-0.13$ & & $10.52 \cdot 16.64$ & $\underline{0.28 \cdot 0.75}$ & $12.67-15.64$ & $5.18-6.53$ & $0.12 \cdot 0.19$ \\
\hline & 44.28 & 0.25 & 20.98 & 0.08 & & 13.38 & 0.42 & 14.42 & 5.93 & 0.16 \\
\hline 27 & $39.51-41.64$ & $0.01 \cdot 0.57$ & $21.31-22.18$ & $0.13-1.61$ & & $14.61 \cdot 20.78$ & $0.86 \cdot 1.67$ & $9.96-15.02$ & $3.64-6.45$ & $0.00-0.10$ \\
\hline & 40.95 & 0.30 & 21.80 & 0.32 & & 17.27 & 1.13 & 13.90 & 4.81 & 0.06 \\
\hline 28 & $39.00-41.10$ & $\underline{0.11-0.26}$ & $16.20 \cdot 20.00$ & $2.30-7.37$ & & $8.22-9.83$ & $0.05-0.40$ & $5.62-14.10$ & $12.30-22.00$ & 0.00 \\
\hline & 40.01 & 0.17 & 18.29 & 4.99 & & 9.12 & 0.13 & 9.85 & 16.76 & \\
\hline 29 & $36.60-38.82$ & $0.00-0.78$ & $18.38-21.30$ & $0.00-0.06$ & & 27.0030 .05 & $0.39-1.10$ & $3.24 \cdot 6.16$ & $6.70 \cdot 8.86$ & $0.00-0.06$ \\
\hline & 37.67 & 0.24 & 20.01 & 0.01 & & 28.61 & 0.55 & 3.89 & 8.13 & 0.03 \\
\hline 30 & $40.17+2.76$ & $0.00-0.19$ & $23.21-25.65$ & $0.00-0.11$ & & $6.47-21.22$ & $0.00-0.13$ & $9.13-20.41$ & $3.94-11.78$ & 0.000 .10 \\
\hline & 41.48 & 0.02 & 24.63 & 0.01 & & 11.38 & 0.02 & 14.99 & 7.88 & 0.03 \\
\hline
\end{tabular}

RESULTADOS Abaixo apresentamos exemplos de resultados do emprego da Metodologia Multidisciplinar de estudo da granada nos três principais campos kimberlíticos (Zolotitskoe, Verkhotinskoe e Kepinskoe) da Província Diamantífera de Arkhangelsk.

Granadas do Campo de Zolotitskoe O banco de dados das granadas do Campo de Zolotitskoe é constituído por 546 análises químicas de 7 diatremas: Pionerskaya, Karpiskiy 1 e 2, Lomonosov, Pomorskaya, Pervomayskaya, Koltsevaya e
Arkhangelskaya. Foram caracterizados morfologicamente mais de 10.000 grãos. Nos diatremas do campo Zolotitskoe predominam as granadas de coloração lilás (violeta) e vermelha, com grãos inteiros e fragmentos de grãos ovais-arredondados com superfície constituída por "altos-baixos" ou pela levemente foscada. As granadas de coloração rosa e laranja ocorrem em quantidades subordinadas na forma de lascas e fragmentos irregulares com superfície levemente foscada. Nos horizontes superiores dos diatremas kimberlíticos, predominam grãos ovalado-arredondados de cor rosa e laranja, com fino micro- 
relevo corrosional da superfície. Estudo posterior dessas granadas permitiu determinar gênese crustal (Vasileva et al.,1989).

Na segunda etapa foram estudadas por espectroscopia óptica absorção cerca de 400 lamínulas de granadas. O estudo comparativo dos parâmetros ópticos e colorimétricos $\left(\lambda_{k}\right.$ e $\left.p_{c}\right)$ e dos espectros ópticos de absorção dessas granadas com os encontrados em Matsyuk et al.(1985), que se basearam em dados obtidos com a análise das granadas de rochas mantélicas de pipes kimberlíticos da Yakutia, República Sul Africana, Lesoto e outros países, permitiu efetuar uma discriminação preliminar das granadas e associá-las a determinados grupos paragenéticos. Determinou-se que as granadas mais freqüentemente encontradas eram as de paragênese ultrabásica associadas a: lherzolitos equigranulares, Iherzolitos cisalhados, harzburgitos, wehrlitos, diopsiditos, websteritos, dunitos; e mais raramente de paragênese eclogítica: eclogitos ferromagnesianos e eclogitos ferromagnesianos diamantíferos. O estudo posterior $\mathrm{em}$ microssonda eletrônica das mesmas lamínulas de granadas permitiu definir com muito maior precisão os limites dos campos dos tipos paragenéticos da granada de Matsyuk et al. (1985), Garanin et al. (1986). A partir dos resultados de análise química por microssonda eletrônica e análise discriminante foi possível identificar 18 grupos químico-genéticos na população de granadas do Campo, cuja freqüência de grupos químico-genéricos é mostrada no histograma da Figura 3.

Constatou-se que a granada altamente cromífera associada a Iherzolitos equigranulares diamantíferos (aproximadamente $19 \%$ da total) deste Campo ocorre com maior freqüência, seguindo-se, em ordem decrescente de ocorrência, a granada de rochas metamórficas crustais (19\%), a granada medianamente cromífera associada a lherzolitos equigranulares diamantíferos
(14\%), a granada de baixo-médio teor de cromo de lherzolitos equigranulares diamantíferos ( $11 \%)$, a granada de baixo cromo associada a lherzolitos e websteritos (10\%), a granada associada a dunitos e harzburgitos altamente diamantíferos $(7,5 \%)$, a granada de ilmenita-rutilo eclogitos ferromagnesianos altamente diamantíferos $(6,5 \%)$, a granada de alto e médio teor de cromo de peridotitos diamantíferos $(4 \%)$ e a granada de ilmenita-rutilo eclogitos magnesianos diamantíferos (2\%). São muito raras as ocorrências de granada associada a wehrlitos diamantíferos (1\%), a alkremitos magnesianos (1\%), a eclogitos ferromagnesianos diamantíferos $(1 \%)$ e a eclogitos aluminosos diamantíferos (1\%). Merece destaque a presença de grande proporção de granadas de paragêneses eclogíticas diamantíferas $(8,9 \%$ de um total de $9,1 \%$ de granadas eclogíticas presentes). Neste Campo, é importante frisar, há o marcante predomínio das paragêneses diamantíferas lherzolíticas sobre as dunítico-harzburgíticas, o que demonstra cabalmente, que nessa província, não se aplicam os critérios de prospecção, pesquisa e avaliação diamantífera de corpos segundo as regras e critérios preconizados por Sobolev (1971 e 1974), Gurney (1986) e Gurney et al. (1993).

Granadas do Campo de Verkhotinskoe O banco de dados das granadas desse Campo é representado por 110 análises químicas. O mineral foi retirado da rocha sã de quatro pipes do Campo de Verzhotinskoe: Volchya-Severnaya, Osetinskaya, Mayskaya e Verkhotina. Foram caracterizados morfologicamente cerca de 900 grãos de granada. Nessas amostras predominam granadas de coloração rosa e laranja. A principal característica das granadas nessas amostras é a má conservação dos seus grãos, causada por fissuramento primário e intenso do

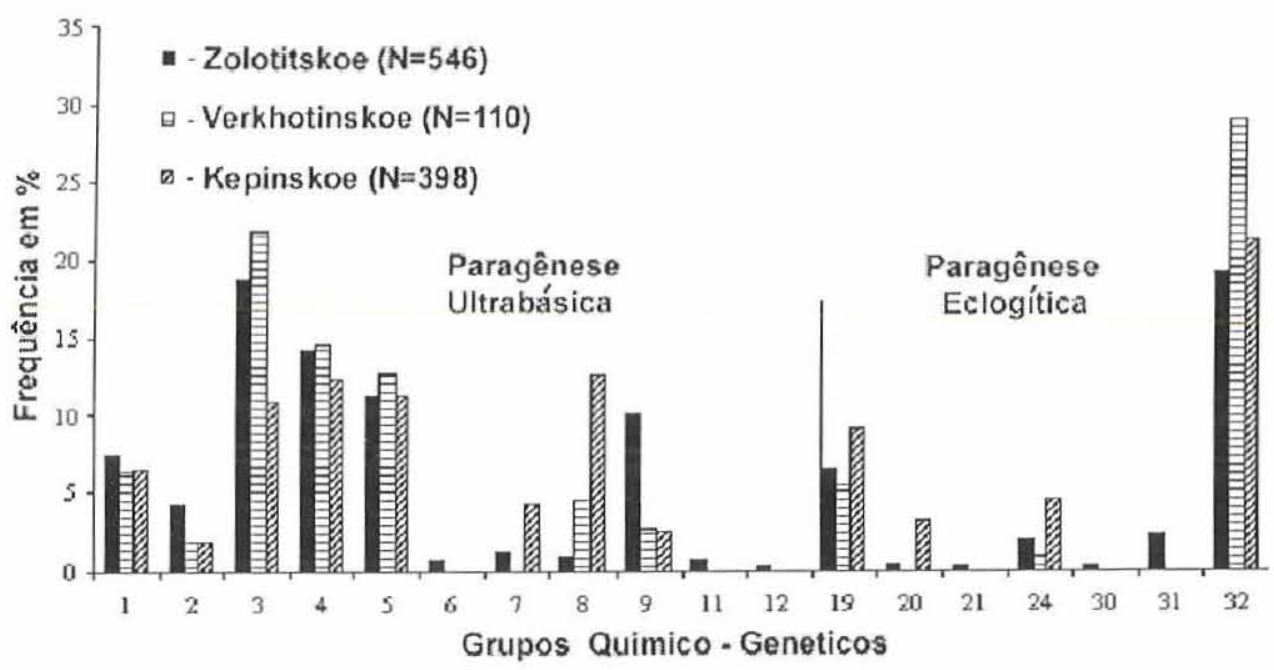

Figura 3 - Histograma de frequiência da granada segundo os grupos químico-genéticos nos campos kimberlíticos de Zolotitskoe, Verkhotinskoe e Kepinskoe ( $N$ - número total de grãos de granada estudados): 1-dunitos e harzburgitos altamente diamantíferos; 2- peridotitos diamantíferos com granada mediana a altamente cromifera; 3- lherzolitos diamantíferos com granada altamente cromífera; 4- Therzolitos equiigranulares diamantíferos com granada medianamente cromífera; 5 - lherzolitos eqüigranulares diamantíferos com granada pouco a medianamente cromífera; 6- wehrlitos diamantíferos; 7- Iherzolitos eqüigranulares (por vezes cisalhados) pouco diamantíferos com granada altamente cromífera, altamente titanífera e altamente cálcica; 8- Ilmenita lherzolitos eqüigranulares (freqüientemente cisalhados) pouco diamantíferos com granada titanífera de baixo cromo; 9lherzolitos e websteritos com granada de baixo cromo; 10-piroxenitos ferromagnesianos \pm ilmeníticos; 11 - alcremitos magnesianos; 12-ilmenita-rutilo eclogitos ferromagnesianos diamantíferos; 13-eclogitos ferromagnesianos diamantíferos; 14eclogitos aluminosos diamantíferos; 15-ilmenita-rutilo eclogitos magnesianos diamantíferos; 16-eclogitóides; 17-granada de gênese discutivel (incerta); 18- granada de rochas metamórficas crustais. 
processo de gretamento hidrotermal pós-intrusão do pipe. Devido à ausência de grãos homogêneos com dimensões adequadas para o preparo de lamínulas, não foi possível obter os espectros ópticos de absorção das granadas desses pipes. Os resultados da análise discriminante estão na figura 3. De acordo com os resultados da análise discriminante, em termos de freqüência, temos, em ordem decrescente, a granada altamente cromífera de lherzolitos equigranulares diamantíferos (22\%), a granada de teor médio de cromo de Iherzolitos equigranulares diamantíferos (14\%), a granada de baixo a médio de cromo de Iherzólitos equigranulares diamantíferos (13\%), a granada de dunitos e harzburgitos altamente diamantíferos $(6,5 \%)$, a granada de ilmenita-rutilo eclogitos ferromagnesianos diamantíferos $(5,5 \%)$ e a granada titanífera de baixo cromo de ilmenita lherzólitos equigranulares freqüentemente cisalhados e fracamente diamantíferos $(4,5 \%)$. Raras são as ocorrências da granada de alto e médio teor de cromo de peridotitos diamantíferos (2\%), da granada de baixo cromo de Iherzolitos e websteritos (3\%) e da granada de ilmenita-rutilo eclogitos magnesianos diamantíferos (1\%).

Por outro lado, convém destacar a alta concentração de granadas de rochas metamórficas crustais (29\%) nas amostras estudadas desse campo, superior, inclusive, a do Campo de Zolotitskoe. Nos kimberlitos do Campo de Verkhotinskoe a variedade de granadas associadas a rochas mantélicas é menor do que no Campo de Zolotitskoe, por eles estarem "infestados" por granadas de rochas metamórficas do embasamento. A proporção de granadas de paragênese altamente diamantífera é de $6,5 \%$, enquanto a de paragênese diamantífera é de $57,5 \%$.

Granadas do Campo de Kepinskoe O banco de dados da composição química das granadas desse Campo consiste de 400 análises referentes principalmente a três grupos de corpos kimberlíticos: Shochinskoe, Kepinskoe e Soyanskoe. Foram caracterizados morfologicamente cerca de 300 grãos de granadas do pipe Shochinskoe, em torno de 900 grãos do grupo de diatremas de Kepinskoe e ao redor de 1.800 grãos oriundos de pipes que se enfeixam no grupo de Soyanskoe. Em todos os corpos predomina a granada oval-arredondada ou de forma irregular com superfície constituída por altos-baixos ou pela finamente mateada. A distribuição das granadas segundo os grupos de coloração é muito diferente entre os pipes dos três grupos. No campo de Shochinskoe predominam granadas de coloração rosa e laranja, enquanto nos diatremas do grupo de corpos de Kepinskoe e Soyanskoe, predominam as granadas vermelhas e lilases, ocorrendo de modo subordinado as granadas de coloração rosa e laranja. É necessário enfatizar que foram achados inúmeros grãos de granada com coroa quelifítica. De acordo com os dados óptico-colorimétricos de 250 lamínulas de granadas, ocorrem nos diatremas do Campo de Kepinskoe grãos de diversas paragêneses minerais, que em ordem decrescente de freqüência (Fig.3) são as seguintes: espinélio peridotitos, Iherzolitos cisalhados, wehrlitos, ilmenita peridotitos, Iherzolitos equigranulares, Iherzolitos com ilmenita e rutilo, harzburgitos e dunitos, eclogitos ferromagnesianos diamantíferos, e raros achados de distênio e coríndon eclogitos.

Pelos resultados da análise discriminante, foi possível identificar dentre as amostras representativas do Campo de Kepinskoe, 12 grupos de granadas (Fig.3). Com maior freqüência aparece a granada titanífera de baixo cromo de ilmenita Iherzolitos equigranulares fracamente diamantíferos que por vezes aparecem cisalhados (13\%), seguida pela granada de teor médio de cromo de lherzolitos equigranulares diamantíferos (12\%), granada de baixo e médio teor de cromo de Iherzolitos equigranulares diamantíferos $(11 \%)$, granada de ilmenita-rutilo eclogitos ferromagnesianos diamantíferos (9\%), granada de dunitos e harzburzitos altamente diamantíferos $(6,5 \%)$, granada de ilmenita-rutilo eclogitos magnesianos diamantíferos $(5 \%)$, granada altamente cálcica altamente cromífera e altamente titanífera de lherzolitos equigranulares pouco diamantíferos (por vezes cisalhados) (4\%), granada de eclogitos ferromagnesianos diamantíferos (3\%); granada de baixo cromo de Iherzolitos e websteritos (2\%). De toda população de granadas estudadas, 6,5\% relacionam-se a paragêneses altamente diamantíferas; $54 \%$ às diamantíferas, sendo que $36 \%$ delas são devidas a granadas de paragênese ultrabásica e $17 \%$ a granadas de paragênese básica (eclogítica). Constatou-se que no Campo de Kepinskoe grande parte das granadas se relaciona parageneticamente a nódulos de ilmenita, a ultrabasitos e a eclogitos portadores de ilmenita.

Assim, por meio do estudo multidisciplinar das granadas foi possível provar o alto potencial diamantífero dos diatremas do Campo Kimberlítico de Zolotitskoe, e dos pipes dos campos de Verkhotinskoe e Kepinskoe. Em cada um dos campos analisados, foram definidas e caracterizadas as paragêneses de minerais mantélicos, incluindo-se no rol, as diamantíferas, e também foram determinadas às relações quantitativas entre os diversos tipos de rochas do manto.

CONCLUSÕES E CONSIDERAÇÕES FINAIS Com base no Método Multidisciplinar aplicado ao estudo da granada em cada um dos três campos kimberlíticos analisados, foi possível determinar a presença de paragêneses de minerais mantélicos. Além disso:

1- pelo método logrou-se identificar e caracterizar granadas pertencentes a grupos químico-genéticos diamantíferos e altamente diamantíferos.

2- entre os campos de Zolotitskoe e Verkhotinskoe foi encontrada uma grande semelhança, tanto nos tipos de paragêneses das granadas quanto nas suas relações quantitativas.

3- no Campo de Zolotitskoe, há marcante predomínio das paragêneses diamantíferas lherzolíticas, sobre as duníticoharzburgíticas, o que demonstra cabalmente, que nessa província, não se aplicam os critérios de prospecção, pesquisa e avaliação diamantífera de corpos segundo as regras e critérios preconizados por Sobolev (1971, 1974), Gurney (1986) e Gurney et al. (1993).

4- no campo de Kepinskoe a maioria das granadas se relacionada parageneticamente a nódulos de ilmenita, e a rochas ultrabásicas e básicas mantélicas portadoras de ilmenita.

5- a quelifitização das granadas do campo de Kepinsk provavelmente se relaciona ao longo tempo de ação agressiva do magma kimberlítico sobre o diamante, fato este que causou sua ulterior dissolução.

6- os resultados da avaliação do potencial diamantífero obtidos por meio do estudo das paragêneses diamantíferas das granadas e suas freqüências estão de pleno acordo com o teor de diamantes encontrado nos pipes kimberlíticos por métodos diretos de avaliação, e também permitem confïmar o zoneamento horizontal da Província Diamantífera de Arkhangelsk, anteriormente delineado por Kudriavtseva et al. (1991). 
7- foi possível efetuar a regionalização mineralógica do território da Província Diamantífera de Arkhangelsk, e caracterizar detalhadamente 67 corpos de: kimberlitos, melilititos e basaltos. Os dados obtidos, no seu conjunto, dão lastro para a continuidade dos trabalhos de prospeç̧ão na região considerada.

Como corolário do trabalho, podemos afirmar que este Mé- todo permite o processamento e tratamento matemático de grandes volumes de dados analíticos num curto espaço de tempo, agilizando o gerenciamento da pesquisa.

Agradecimentos Os autores agradecem ao Prof. Márcio Masatoshi Kondo e aos revisores da RBG pelas sugestões de aprimoramento da forma do texto.

\section{Referências}

Afanasev V.P. 1991. Princípios da prospeç̧ão de jazidas diamantíferas com base nos concentrados de bateia. Tese de Doutoramento.TsNIGRI. Moscou. Resumo 43 pp. (em russo).

Afanasev V.P., Garanin V.K., Kudryavtseva G.P., Posukhova T.V. 1986. Atlas das características morfológicas dos minerais satélites do diamante. YaOKI TsNIGRI-MGU. Mirny.87pp. (em russo)

Berlinskiy A.I. 1988. Separação de Minerais.Nedra. Moscou. 229 pp. (em russo)

Berlinskiy A.I. 1991. Métodos de análise e tecnologia de tratamento de amostras durante a prospeçāo e pesquisa de jazidas diamantiferas. TsNIGRI.Moscou. 126 pp. (em russo)

Bogatikov O.A., Garanin V.K., Kononova V.K., Kudryavtseva G.P., Vasileva E.P., Verzhak V.V., Verichev E.M., Parsadanyan K.S., Posukhova T.V. 1999. Provincia Diamantifera de Arkhangelsk (Geologia. Geoquímica. Petrologia e Mineralogia). MGU. Moscou. 524 pp. (em russo)

Dawson J.B. \& Stephens W.E. 1975. Statistical analysis of garnets from kimberlites and associated xenoliths. Journal of Geology: 83:589-607

Garanin V.K., Krot A.N., Kudryavtseva G.P., Vuyko V.N., Gracheva N.V., Mineeva, Yu.M. 1986. Paragêneses minerais da granada de rochas de diatremas de uma das regiôes da URSS. Dados da XIII Conferência de Jovens Cientistas. Mineralogia dos Kimberlitos e de Rochas Congêneres. Moscou. VINITI. N6967-B-86. pp .26-45. (em russo)

Garanin V.K., Krot A.N., Kudryavtseva G.P. 1990. Cluster Analysis como uma das abordagens para classificação da granada de kimberlitos. Dados da XVI Conferência de Jovens Cientistas. Série Banco de Dados. Características da Composição Química e Classificação da Granada de Kimberlitos. Moscou. VINITI. n.p.(em russo)

Garanin V.K., Kudryavtseva G.P., Marfunin A.S., Mikhaylichenko Yu.M. 1991. Inclusões no Diamante e Rochas Diamantíferas. Editora MGU, Moscou. 240pp. (em russo)

Garanin V.K., Kudryavtseva G.P., Mineeva Yu.P. 1991. Composição e gênese das coroas quelifíticas na granada da série do piropo em diatremas da Província Kimberlítica de Arkhangelsk. Vestnik Moskovskogo Gosudarstvenogo Universiteta Seriya Geologia, 6:64-75. (em russo)

Garanin V.K. \& Kudrjavtseva G.P.1991. New technology of search of diamond bearing kimberlites methodological basis and fields of applications. $\ln : 5^{\text {th }}$ International Kimberlite Conference, Extended Abstracts. Araxá, pp. 505 507.

Garanin V.K., Kudrjavtseva G.P., Laverova T.N.199I. The comparative characteristics of ilmenite from the kimberlite provinces of the URSS. $\ln : 5^{\text {th }}$ International Kimberlite Conference, Extended Abstracts. Araxá, pp. 508 510.

Garanin V.K., Kudrjavtseva G.P., Michailichenko O.A.1991. Mineralogy of oxides from ground mass of kimberlites of Jakutia and northern European part of the USSR. In: $5^{\text {th }}$ International Kimberlite Conference, Extended Abstracts. Araxá, pp. 511-513.

Garanin V.K., Kudrjavtseva G.P., Vasileva E.P.1998. The fundamental study of garnets: application for prospecting and economical estimation of diamond bearing kimberlites. In: $7^{\text {th }}$ International Kimberlite Conference, Extended Abstracts. Cape Town, pp.236-238.

Gurney J.J. 1984. A correlation between garnet and diamond in kimberlites. In: Glover J.E. Harris P.G. (Eds). Kimberlites occurrences and origin: a basis for conceptual models in exploration. University of Western Australia. Publication 7. Perth. pp. 143-166.
Gurney J.J., Helmtaedt, H., Moore R.O. 1993. A review of the use and application of mantle mineral geochemistry in diamond exploration. Pure \& Applied Chemistry. 68:2423-2442.

Iwanuch W., Matsyuk S.S., Taran M.N. 1999. Espectros ópticos de absorção e dados colorimétricos de granadas de granadas gemológicas da bacia do rio Santo Antonio, Município de Coromandel-MG. Revista Brasileira de Geociências, 29:491-496.

Jago B.C. \& Mitchell R.H. 1986. The statistical classification of kimberlite garnet by divisive cluster analyses and multiple discriminant analyses. $\ln : 4^{\text {th }}$ International Kimberlite Conference, Extended Abstracts. Perth, pp .42-45.

Kharkiv A.D. 1978. Princípios dos métodos mineralógicos de prospeç̧ão de jazidas diamantíferas. Moscou. 135pp. (em russo).

Kharkiv A.D., Zinchuk N.N., Kryuchkov A.I. 1995. Bases geológico-genéticas do método mineralógico de prospeção de jazidas diamantíferas a partir dos concentrados de bateia. Nedra. Moscou. 315 pp. (em russo).

Kudryavtseva G.P., Bushueva E. B., Vassileva E.R., Verichev E.M, Garanin V.K., Grib V.P., Laverova T.N., Michailichenko O.A., Posukhova T.V. Schepina N.A. 1991. Geological structure and mineralogy of the kimberlites of the Arkhangelsk Kimberlite Province. In: $5^{\text {th }}$ International Kimberlite Conference, Extended Abstracts.Araxá, Brasil, pp. 530-532.

Matsyuk S.S., Platonov A.N., Khomenko V.M. 1985. Espectros Ópticos e Coloração de Minerais Mantélicos de Kimberlitos. Naukova Dumka. Kiev. $245 \mathrm{pp}$. (em russo)

Matsyuk S.S. 1992. Cristaloquímica e Tipomorfismo de Minerais de Rochas do Manto. (Segundo Dados de Espectroscopia Óptica). Tese de Doutoramento. Instituto de Geoquímica e Física dos Minerais. Academia de Ciências da Ucrânia. Kiev.300pp. (em russo)

Safronov A.F. \& Nikolaev N.S. 1985. Comparação estatística de granadas de rochas kimberlíticas e xenólitos mantélicos. In: Oleynikov B.V., Nikishov K.N., Kovalskiy V.V. et al. (Eds.)1985. Aspectos da evolução petrológicogeoquímica dos sistemas magmáticos kimberlítico e básico. YaF SO AN SSR. Yakutsk. pp. 38-50. (em russo)

Sobolev N.V. 1971. Acerca dos critérios mineralógicos de avaliação do potencial diamantífero de kimberlitos. Geologiya i Geofizika.12:70-78. (em russo)

Sobolev N.V. 1974. Deep seated inclusions in kimberlites and problem of the composition of the upper mantle. AGU. Washington DC. Tradução para o inglês por Brown D.A.,1977.

Vasileva E.P., Verzhak V.V., Garanin V.K., Gracheva N.V., Kudryavtseva G.P. 1989. Estudo multidisciplinar da granada de coloração laranja de um dos diatremas kimberlíticos da URSS. Novos Dados de Minerais. 35:21-35. (em russo)

Zakharova E.M 1989. Utilização do método dos concentrados de bateia na prospeç̧̃o de minerais úteis.Nedra. Moscou.161 pp. (em russo)

Zolnikov G.V., Ponomarenko A.I., Zelenova G.M. 1981. Experiência em classificar granadas de kimberlitos e xenólitos do pipe Mir. In: Kovalskiy V.V.(Ed.).1981. Parageneses de minerais de rochas kimberliticas. YaF SO AN SSR. Yakutsk. pp. 29-35. (em russo)

Zubarev B.M. (Ed.).1984. Métodos de amostragem e processamento de amostras durante a prospeção e pesquisa de jazidas de diamantes. Nedra. Moscou. (em russo)

Manuscrito A-1299 Recebido em 22 de novembro de 2001 Revisão dos autores em 17 de dezembro de 2001 Revisão aceita em 19 de dezembro de 2001 